\title{
Advances and directions in chemotherapy using implantable port systems for colorectal cancer: a historical review
}

\author{
Yasuhiro Inoue • Masato Kusunoki
}

Received: 20 March 2013 / Accepted: 3 July 2013/Published online: 28 July 2013

(c) The Author(s) 2013. This article is published with open access at Springerlink.com

\begin{abstract}
With the recent advances in chemotherapy for colorectal cancer, the prognosis for patients with metastatic colorectal cancer has been significantly improved. The development of the implantable port system has also enabled patients to receive multiagent chemotherapy with a more satisfactory quality of life. Historically, chemotherapy using implantable port systems was begun to obtain an oncological benefit in the treatment of locoregional cancer. In the 1950s, there was an increasing interest in perfusion techniques for the application of chemotherapeutic agents, such as nitrogen mustard, in the locoregional treatment of metastatic cancer. Among them, the treatment of liver metastasis has interested oncologists for many years. On the other hand, implantable devices were developed during the intervening decades that have enabled patients with colorectal cancer with liver metastases to be treated effectively using hepatic arterial infusion; which became more common in the 1980s. The treatment of metastatic colorectal cancer increasingly requires a multimodal approach and multiple treatment options based not on convenience, but in terms of personalization and efficacy. Therefore, it is important to optimize the pharmacokinetics of chemotherapeutic agents. Implantable port systems for colorectal cancer patients have been essential for oncological practice, and the importance of these systems will remain unchanged in the near future.
\end{abstract}

\footnotetext{
Y. Inoue $(\bowtie) \cdot M$. Kusunoki

Department of Gastrointestinal and Pediatric Surgery,

Division of Reparative Medicine, Institute of Life Sciences,

Mie University Graduate School of Medicine,

2-174 Edobashi, Tsu, Mie 514-8507, Japan

e-mail: yasinoue@clin.medic.mie-u.ac.jp
}

Keywords Colorectal cancer - Chemotherapy · Implantable port system

\section{Introduction}

Over the past several decades, many management changes in oncology have occurred, especially in chemotherapy for colorectal cancer (CRC). From the early predominance of bolus injections of 5-fluorouracil (5-FU), chemotherapy has made considerable progress for CRC, including the biochemical modulation of the 5-FU effect by leucovorin, the development of infused 5-FU/leucovorin regimens and the introduction of irinotecan and oxaliplatin. Furthermore, the development of active cytotoxic chemotherapy regimens that incorporate biological targeted agents for metastatic CRC has significantly improved the survival periods of patients with metastatic CRC to more than 2 years [1-3]. Therefore, the main aims of modern chemotherapy for metastatic CRC have become the prolongation of survival and a better quality of life. In addition, modern chemotherapy using various combination regimens has become widely accepted as implantable port systems and disposable infusion pumps have been developed [4].

Easy-to-handle port systems are currently an important part of clinical practice in oncology. The history of chemotherapy using implantable port systems has three streams: (1) locoregional cancer therapy, (2) drug delivery and (3) implantable devices (Table 1). In the 1950s, there was increasing interest in the perfusion and infusion techniques for the application of chemotherapeutic agents, such as nitrogen mustard, in the locoregional treatment of metastatic cancer. Among them, treatment of liver metastasis has interested oncologists for many years, because it seems that, although the liver is a primary site of blood-borne 
Table 1 The history of implantable port systems

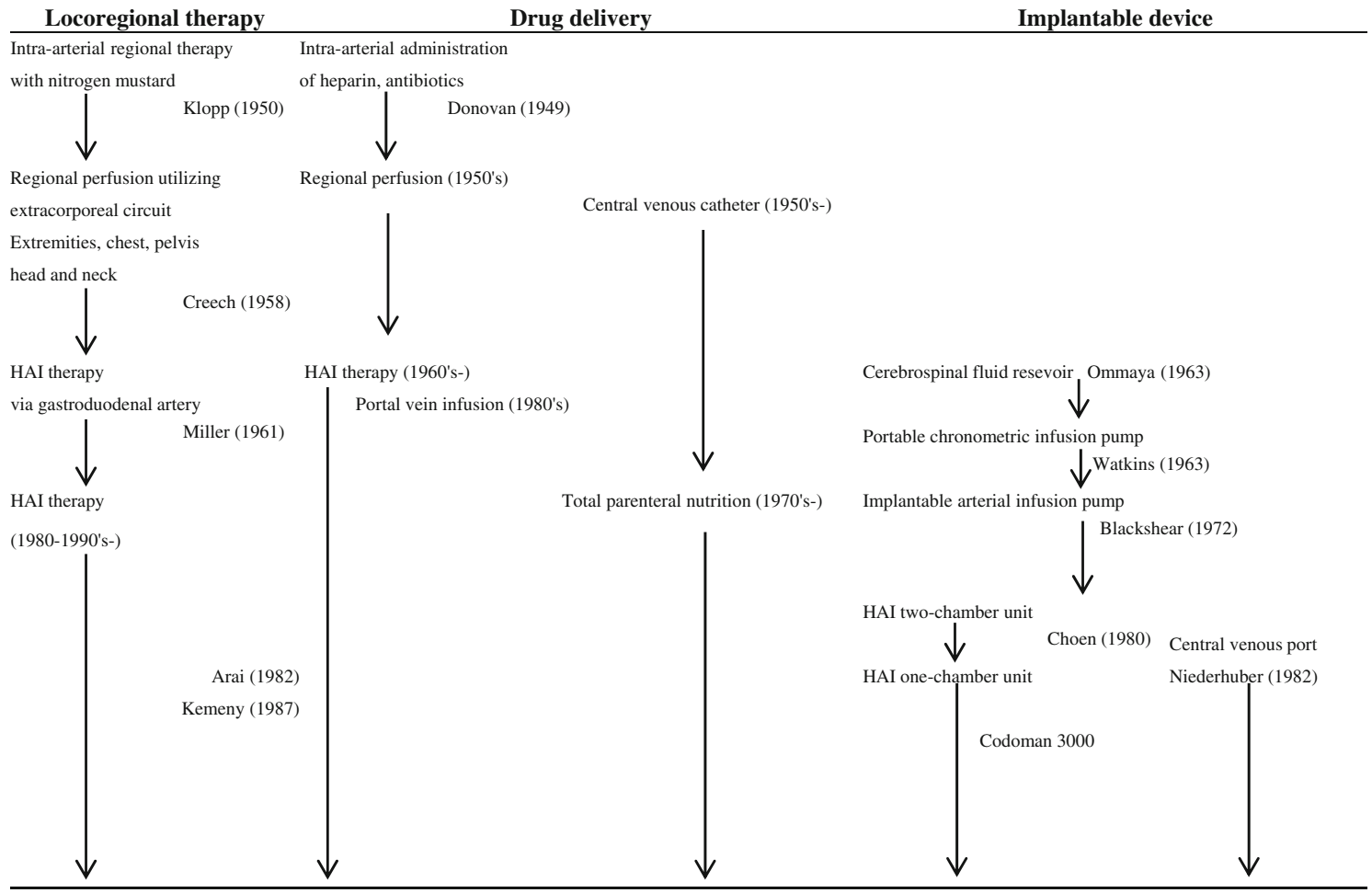

$H A I$ hepatic arterial infusion

metastases, it is often the only site of metastatic disease, especially in patients with CRC. Implantable devices have been further developed during the last few decades, and this has enabled patients with CRC with liver metastases to be treated effectively by locoregional therapy using hepatic arterial infusion (HAI); which became more common in the 1980s. With several lines of chemotherapy currently available for metastatic CRC, central venous catheters and implantable port systems are used worldwide. This article comprises a historical review of the progress made in chemotherapy for metastatic CRC from the viewpoint of the development of implantable port systems. It also discusses the current and future directions in chemotherapy for CRC using implantable port systems.

\section{History of locoregional cancer therapy}

The first clinical application of cytotoxic chemotherapy for malignancies can be traced back to the 1940s, with the introduction of nitrogen mustard [5]. At that time, the limiting factor in the use of mustard compounds was their toxic effect on normal tissues. To avoid these systemic toxic effects, Klopp et al. [6] proposed the use of intraarterial cancer chemotherapy with nitrogen mustard in 1950. A suitable technique was developed by utilizing a method devised for the intra-arterial administration of heparin [7], and polyethylene tubes were introduced into the external carotid artery. Next, the locoregional cancer therapy evolved into regional perfusion utilizing an extracorporeal circuit. In 1958, Creech et al. [8] employed the technique in 24 patients with various malignant neoplasms, and concluded that the administration of chemotherapeutic agents by perfusion is useful for localized tumors and for palliation of certain far-advanced lesions. As interest in locoregional infusion techniques increased, treatment of liver metastasis began to interest oncologists in the 1960s, because it seemed that although the liver is a primary site of blood-borne metastases, it is often the only site of metastatic disease, especially in patients with CRC.

While work with hepatic resection was proceeding, other groups were beginning to look carefully at the regional infusion of chemotherapy for liver metastases. However, hepatic arterial catheterization sometimes presented difficulties because of the extent of the disease. In 1961, a simple method of catheterization of the hepatic artery through the gastroepiploic and gastroduodenal arteries was first described by Miller et al. [9], who were the pioneers of the modern HAI technique. Since Watkins [10] developed the portable chronometric infusion pump to concentrate the administration of large doses of drugs to the liver in 1963, extensive clinical experience with 


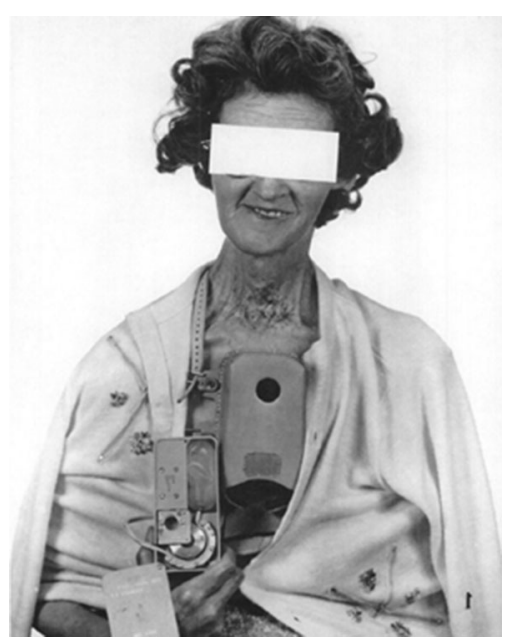

Fig. 1 A chronometric ambulatory infusion apparatus. A disposable plastic bag serves as a reservoir for a concentrated solution of drug. Reprinted with permission from the American Association for Cancer Research [13]

regional infusion chemotherapy of hepatic tumors has been reported [11, 12]. Figure 1 shows a miniature portable chronometric infusion pump (Watkins USCI Chronofusor; United States Catheter \& Instrument Corp., Glens Falls, New York) developed by Watkins et al. [10, 13]. Most experiences have involved percutaneously placed hepatic artery catheters connected to extracorporeal pumps. However, these systems have been associated with mechanical and infectious complications [14]. In the 1970s, a reliable, totally implantable device was developed for long-term intravascular drug infusion $[14,15]$. The initial application of the pump was for long-term heparin infusions in patients with refractory thromboembolic disease [16]. With regard to cancer therapy, regional infusion of chemotherapy for liver metastases was expected to be oncologically useful. Thus, HAI chemotherapy for liver metastases from CRC became widely adopted in the 1980s.

\section{HAI chemotherapy for CRC}

\section{Rationale for HAI}

The rationale for hepatic arterial therapy is based on the fact that once liver metastases grow beyond $3 \mathrm{~mm}$, they are fed predominantly by the hepatic artery, whereas normal hepatocytes are fed predominantly by the portal vein [17]. The liver may be the initial stop for metastatic spread through the portal vein, and early postoperative regional administration of chemotherapeutic agents into the portal vein might be particularly beneficial, destroying suspected tumor cells in the liver before established tumor growth can take place. However, from 1980 until the 1990s, several randomized trials failed to show significant differences in the survival benefit between portal vein infusion and systemic chemotherapy after curative surgery for advanced CRC [18-20].

\section{Clinical evidence of HAI chemotherapy for CRC}

On the other hand, HAI for liver metastases from CRC was widely used based on several lines of evidence during the same period. HAI therapy is associated with not only antitumor effects, but also hepatic toxicity, and extensive studies have been performed to identify the optimal agents. Agents that are taken up by the liver and have high firstpass extraction, as well as high total-body clearance, are the most useful agents. The most active drug was shown to be 5-fluoro-2-deoxyuridine (FUDR), which has a 60-90\% first-pass liver extraction rate and an estimated 100- to 400-fold increase in hepatic exposure when used for HAI [21]. Several randomized trials from the 1980s to 2000 were performed to compare HAI using FUDR with systemic chemotherapy for unresectable liver metastases from CRC. The results suggested that HAI using FUDR was well tolerated and associated with a significantly better response rate compared with systemic chemotherapy using 5-FU in the treatment of metastases from CRC, although the survival benefit was limited. A meta-analysis combining the results of seven trials also supported the use of HAI using FUDR in the treatment of unresectable liver metastases from CRC [22]. A significantly higher response rate of $41 \%$ was obtained with HAI using FUDR compared with a $14 \%$ response rate with systemic 5-FU. In these previous reports, the median survival was significantly increased to 16 months with HAI versus 13 months with systemic treatment.

Multimodal therapy using HAI for unresectable liver metastases

The hepatic resection criteria have been expanded with advances in surgical techniques; however, only $15-20 \%$ of patients have disease that is suitable for resection at the time of presentation [23]. However, a proportion of tumors may become resectable after they respond to preoperative chemotherapy. Patients with potentially resectable liver metastases are now treated with conversion therapy using modern systemic chemotherapy, often a triple-drug cytotoxic regimen with molecular targeted agents, to maximally downsize the disease and subsequently facilitate curative surgical resection of the metastases [24, 25]. The conversion strategy stems from HAI therapy for liver metastases from CRC. HAI is characteristic in that high response rates can be achieved despite the fact that no modern active agents can increase the resection rates for 
initially unresectable liver metastases. Several studies have shown the efficacy of neoadjuvant HAI chemotherapy in patients with initially unresectable liver metastases from CRC [26]. High response rates of 16-90\% using HAI correlated with the complete hepatic resection rates. These results suggest that both locoregional drug delivery and optimization of the pharmacological effects are important for metastatic CRC therapy.

\section{Pharmacokinetics of HAI chemotherapy}

The pharmacokinetics of 5-FU are influenced by the dose and schedule of administration. Short-term, high-concentration exposures are thought to favor RNA-directed 5-FU toxicity, whereas DNA-directed effects are felt to be more prominent with longer exposures to lower drug concentrations [27-29]. These pathways are not mutually exclusive, and more than one mechanism of action may contribute to cytotoxicity. This may support the recent standard intravenous 5-FU regimens comprising bolus plus infusional 5-FU in combination with leucovorin, derived from the DeGramont regimen [30]. Kusunoki et al. [31] reported another promising approach using oral fluoropyrimidines as pharmacokinetic modulating chemotherapy, the pharmacokinetic concept of which resembled that of the DeGramont regimen.

The concept of pharmacokinetic modulation is that the benefit of a continuous 5-FU infusion could be potentiated by low-dose oral uracil/tegafur (UFT), and the wide variation of 5-FU concentrations in each patient requires an implantable port system to achieve optimal concentrations. This pharmacokinetic modulating chemotherapy regimen has been proven to be highly effective for treating CRC [31, 32]. Its efficacy is based on the fact that the pharmacokinetic modulation targets at least two different phases of the cell cycle, depending on the dose of 5-FU [33]. HAI efficacy and other problems in patients with CRC with liver metastases have also been reported from a pharmacokinetic viewpoint [34]. In one study, HAI via an implantable port system comprised perfusion 5-FU for two consecutive days per week at $600 \mathrm{mg} / \mathrm{m}^{2} /$ day and oral administration of UFT at $400 \mathrm{mg}$ /day. HAI using pharmacokinetic modulating chemotherapy significantly decreased the incidence of hepatic recurrence after curative resection, but not the incidence of lung recurrence [34]. The authors stated that the maximum plasma concentration of 5-FU in the HAI group reached $144 \mathrm{ng} / \mathrm{mL}$, which was lower than the $400 \mathrm{ng} / \mathrm{mL}$ reached in the systemic chemotherapy group, and discussed how the pharmacokinetics might lead to an oncological limitation of locoregional therapy. In other words, HAI chemotherapy might have an important role as an oncological strategy when combined with modern systemic chemotherapy or when used as part of multimodal therapy.

\section{Development of port devices}

Implantable port devices for HAI

The implantable port device was originally described in 1963 by Ommaya $[35,36]$ as a cerebrospinal fluid reservoir and manual pump (Fig. 2). The device was introduced to facilitate repeated injections of drugs into the cerebrospinal fluid of patients with fungal meningitides [37]. The device subsequently proved to be of considerable mechanical value in the treatment of malignant neoplasms of the nervous system by allowing the perfusion and instillation of cytotoxic agents $[38,39]$. An implantable pump system that allows for continuous infusion of drugs, including heparin, was developed in 1972 [40]. The pump was a titanium disc about the size and shape of a small ice hockey puck (Fig. 3). The hollow titanium disc was divided into two chambers by a flexible titanium bellows. The first use of this device to deliver chemotherapeutic agents to hepatic tumors was reported in 1980 [41]. It proved very reliable, without mechanical complications, and was rarely subject to the problems seen with percutaneously placed catheters that are left in place for prolonged infusion. After the implantable port device went into production in the 1970s, HAI was more commonly performed.

The development of the non-battery-powered mechanism for a totally implantable HAI pump allowed for the use of HAI as a long-term therapy. In 1980, Cohen et al. [42] reported transbrachial hepatic arterial chemotherapy using a modern implantable infusion pump. The Infusaid $^{\circledR}$ implantable pump (Metal Bellows Corporation, Sharon,

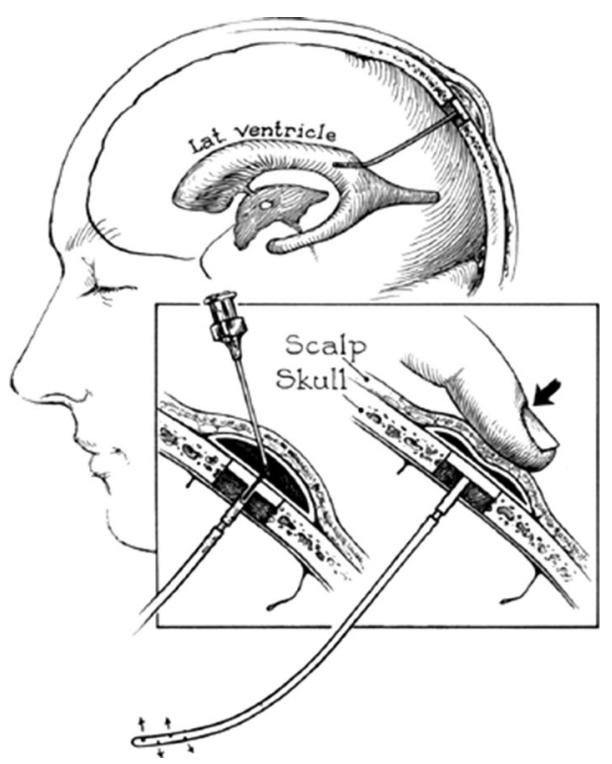

Fig. 2 A diagram of a cerebrospinal fluid reservoir connected to the lateral ventricle, showing the method of use. Reprinted with permission from the Massachusetts Medical Society [36] 
Massachusetts) was a hockey-puck-sized ( $9 \mathrm{~cm}$ in diameter, $2 \mathrm{~cm}$ thick) titanium shell encasing welded titanium. The implantable pump had a $50-\mathrm{cm}^{3}$ reservoir and a side port by which one could directly inject drugs into the catheter. The basic design of the pump was a two-chambered unit made of titanium [43] (Fig. 4). One chamber was a drug fluid chamber that could be accessed from the outside of the pump. The other chamber was charging fluid chamber that was filled with Freon. The mechanism driving the pump involved mechanical energy that was supplied during each refill of the pump. The fluid to fill the pump would be placed into the drug chamber by means of a percutaneously placed needle. This would fill up the drug chamber and push out the bellows that compressed the charging chamber. The compressed Freon would also expand with body heat, then exert its energy by pushing up on the diaphragm in the device, which would slowly push fluid out through the catheter of the pump. After the Infusaid ${ }^{\circledR}$ implantable pump was developed, other pump designs with different mechanisms appeared to further miniaturize these devices, some of which could only be accessed from the central needle inlet

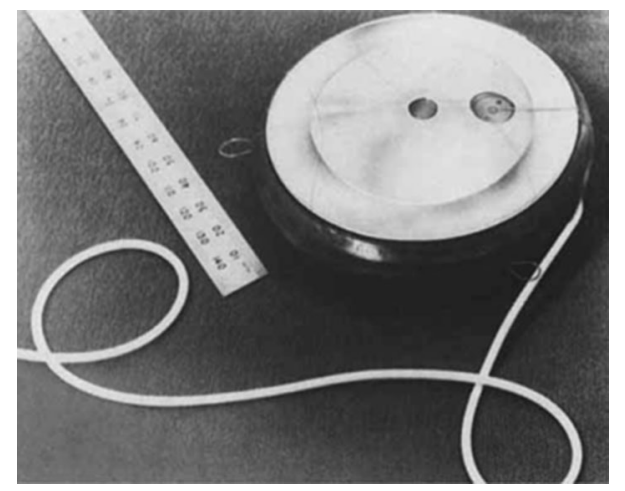

Fig. 3 An implantable infusion pump. Dimensions: $2.82 \mathrm{~cm}$ height $\times 8.43 \mathrm{~cm}$ diameter. The empty weight was $184 \mathrm{~g}$. This material is reproduced with the permission of the American Cancer Society and John Wiley \& Sons, Inc [41]
[44]. The Codman Constant Flow Infusion Pump was designed with a raised septum at the center of the device that can be easily palpated through the skin, making the refill septum more accessible (Fig. 5). This also allowed for much easier detection should a pump invert within the pocket. The safety of use and the efficacy of treatment for regional chemotherapy and pain control were reported previously [45-48].

HAI treatment was initially performed by means of a catheter that was surgically placed in the hepatic artery after isolation of the gastroduodenal artery, and the catheter was then connected to the port placed in a subcutaneous pocket $[49,50]$. To access the artery more easily, Arai et al. [51] reported a radiological method with which to place an implantable catheter by surgical cut-down of the small branch of the subclavian artery in 1982. In 1990, Kumada et al. [52] also reported a technique created by modifying Arai's method so that arterial access could be directly obtained under sonographic guidance. These minimally invasive ways of implanting an infusion catheter for chemotherapy contributed to the widespread use of HAI treatment for liver metastases from CRC.

Central venous port systems

Historically, implantable port systems were developed without distinction between hepatic arterial or central venous access. However, there was a difference in the original aim of drug delivery systems between HAI and central venous access. Whereas HAI via implantable port systems was developed for long-term oncological treatment, central venous port systems were developed for several reasons, including repeated administration of chemotherapeutic agents, parental nutrition, transfusions, infusions, injections and/or blood sample collection. Consequently, central venous port systems play a key role in modern oncology, especially in chemotherapy for patients
Fig. 4 A cross-sectional diagram of the Infusaid ${ }^{\circledR}$ pump. Reprinted with permission from the American Diabetes Association [43]

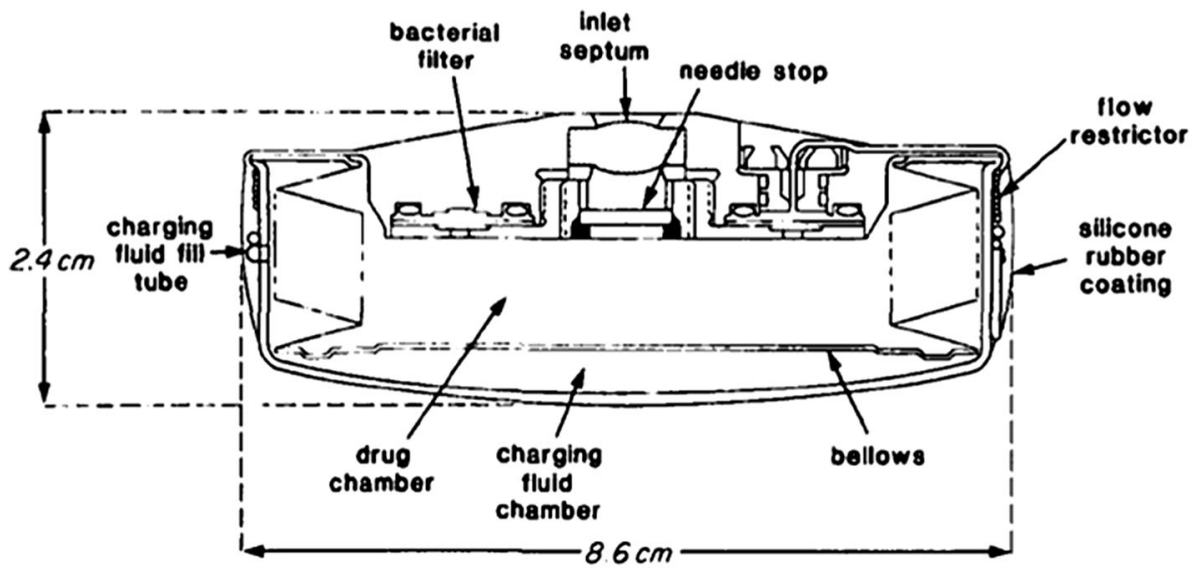

Empty Weight $=181 \mathrm{~g}$ 


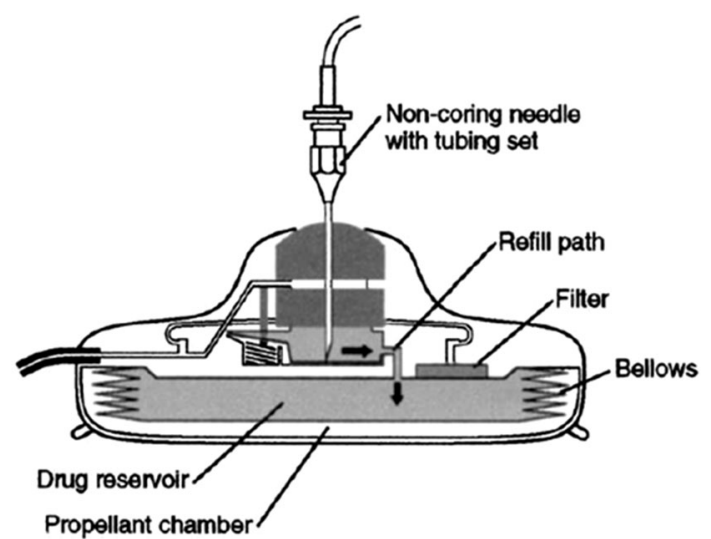

Fig. 5 A schematic diagram of an implantable pump. Reprinted with permission from Elsevier Ltd. [44]

with metastatic CRC. Frequent puncturing of peripheral veins and the local effects of chemotherapeutic drugs cause damage, thrombosis and sclerosis of vascular walls, and the use of port systems for permanent central venous access allows patient to continue long-term treatment.

The first central venous catheters developed were percutaneous, non-tunneled catheters, which came into use in the 1950s [53]. The first long-term central venous catheter was used for parenteral nutrition in 1973 [54]. With regard to oncological use, the Hickman [55] catheter, a long-term venous access device, was used for chemotherapy for the first time in 1979. Open, tunneled central venous catheter systems, such as the Hickman catheter, are associated with a higher infection rate because the end of the catheter remains outside the body. Implantable port systems have advantages in that the puncturing needle can be removed after each injection, and the skin covering the port serves as a natural protection against infection. The currently used central venous port system was introduced to clinical use in 1982 by Niederhuber et al. [56]. The device, an injection port (Infuse-A-Port; Infusaid Corp., Sharon, Massachusetts), comprises a $3.5 \times 1.5 \mathrm{~cm}$ conical chamber with a self-sealing silicon rubber septum connected to a Silastic catheter. This totally implanted venous and arterial access system was initially tested in 30 patients with cancer. A variety of anticancer agents was administered without difficulty, and patient acceptance was excellent.

The Infuse-A-Port had advantages in terms of its size and cost compared with the above-mentioned Infusaid ${ }^{\circledR}$ implantable pump with its complex mechanism. In the early 1980s, both the Infuse-A-Port and Infusaid ${ }^{\circledR}$ implantable pumps were introduced in Japan by Miura et al. [57]. Over the last few decades, central venous port systems have been implanted during minimally invasive procedures by surgeons or interventional radiologists. Implantable central venous port systems therefore facilitate safe and easy blood access in oncology today, although several relevant long-term complications exist, as described below.

Complications associated with central venous ports

There are several important complications associated with central venous ports [58, 59]. Port complications can be subdivided into procedural complications, catheter-related complications and vascular complications. Short-term complications include accidental arterial puncture, hematoma, air embolism, pneumothorax or vessel perforation [60], but these complications are rare in modern oncology. Surgical complications arise in $<2 \%$ of cases in experienced hands [61]. Clinical oncologists are currently most often concerned with major long-term complications associated with the use of catheters in chemotherapy. A retrospective study by Yildizeli et al. [62] showed that among 225 implantable port systems, the long-term complications included infection $(2.2 \%)$, thrombosis $(1.3 \%)$, extravasation $(1.3 \%)$ and catheter fracture $(2.2 \%)$. The major long-term problems of catheter use in patients with cancer are catheter-related infection and thromboembolic complications. Both complications may lead to significant morbidity and impairment of the patient's quality of life.

The catheter-related infection rates in recent studies ranged from 0.8 to $7.5 \%$ [63, 64]. The incidence of catheter-associated thrombosis in patients with cancer varies considerably between studies and patient or cancer type, with the incidence of catheter-associated thrombosis among several studies varying widely from 12 to $64 \%$ [65-69]. Several researchers evaluated the benefit of anticoagulant prophylaxis with either low molecular weight heparin or warfarin in patients with cancer using central venous devices; however, routine anticoagulation cannot be recommended [69-73].

\section{Importance of pharmacokinetics in the chemotherapy for CRC}

Even in modern chemotherapy using several active agents, 5-FU plays a central role in the treatment of CRC, and many attempts have been made to improve its efficacy and potentiate its action over the last 50 years. In particular, recent reports suggested that the pharmacokinetics of 5-FU remain an important factor that affects the prognosis of patients with CRC, even after the introduction of modern chemotherapy for CRC [74-77]. An implantable port system is indispensable in both HAI and central venous port systems to optimize the pharmacokinetics in multiagent chemotherapy. This is important, because the treatment of advanced CRC increasingly requires a multimodal approach. A recent trend highlights the possibility of using 
active first-line chemotherapy to affect the downstaging of metastases and so enable curative surgery for initially unresectable disease, especially liver metastases from CRC $[24,25,78]$. From a pharmacological viewpoint, both doseand time-dependent administration of chemotherapeutic agents is possible via implantable port systems, thus resulting in high response rates in many situations.

On the other hand, recent attention has been given to portfree chemotherapy using oral fluoropyrimidines, such as capecitabine, because of their convenience. Capecitabine is a unique fluoropyrimidine carbamate that is selectively converted to 5-FU in tumors through a cascade involving three enzymes [79]. Using a rational design and taking advantage of the unique tissue localization patterns of these key enzymes, capecitabine was developed to be selectively activated within tumor tissues. Indeed, CapeOx with bevacizumab as port-free chemotherapy showed high response rates ranging from 50 to $78 \%$ and a high conversion rate of $40 \%$ for initially unresectable hepatic metastases [80, 81]. However, recent evidence shows that there are few choices regarding port-free chemotherapy, especially first-line chemotherapy, for advanced or metastatic CRC. Besides CapeOx with bevacizumab, the other recommendations for first-line chemotherapy for advanced or metastatic CRC in the NCCN guidelines include FOLFOX \pm bevacizumab, FOLFIRI \pm bevacizumab, FOLFIRI \pm ant-EGFR antibody, 5-FU + leucovorin + bevacizumab and FOLFOXIRI; all require central venous port systems [82].

\section{Conclusion}

Modern chemotherapy using various combinations of regimens for advanced CRC became widely accepted with the development of the implantable port system. Historically, chemotherapy using implantable port systems was begun for the purpose of locoregional cancer therapy to obtain further oncological benefits. This concept resembles that of modern chemotherapy, which aims to optimize the pharmacokinetics of chemotherapeutic agents. The treatment of advanced CRC increasingly requires a multimodal approach and multiple treatment options, which are based not only on convenience, but especially on personalization and efficacy. Implantable port systems for CRC have been essential for oncological practice, and the oncologic importance of these systems will remain unchanged in the near future.

Acknowledgments We thank Dr. Tsuyoshi Miura at Miura Hospital for advice regarding the historical review of hepatic arterial infusion chemotherapy.

Conflict of interest The authors have no conflicts of interest to declare.
Open Access This article is distributed under the terms of the Creative Commons Attribution License which permits any use, distribution, and reproduction in any medium, provided the original author(s) and the source are credited.

\section{References}

1. Hurwitz H, Fehrenbacher L, Novotny W, Cartwright T, Hainsworth $\mathrm{J}$, Heim $\mathrm{W}$, et al. Bevacizumab plus irinotecan, fluorouracil, and leucovorin for metastatic colorectal cancer. N Engl J Med. 2004;350:2335-42.

2. Van Cutsem E, Köhne CH, Hitre E, Zaluski J, Chang Chien CR, Makhson A, et al. Cetuximab and chemotherapy as initial treatment for metastatic colorectal cancer. N Engl J Med. 2009; 360:1408-17.

3. Fuchs CS, Marshall J, Mitchell E, Wierzbicki R, Ganju V, Jeffery $\mathrm{M}$, et al. Randomized, controlled trial of irinotecan plus infusional, bolus, or oral fluoropyrimidines in first-line treatment of metastatic colorectal cancer: results from the BICC-C study. J Clin Oncol. 2007;25:4779-86.

4. Sawayama H, Hayashi N, Watanabe M, Takamori H, Beppu T, Baba $H$. The central vein access port and catheter in outpatient chemotherapy for colorectal cancer: a retrospective study of 101 patients. Surg Today. 2012;42:29-34.

5. Karnofsky DA, Abelmann WH, Craver LF, Burchenal JH. The Use of Nitrogen Mustard in the Palliative Treatment of Carcinoma: With Particular Reference to Bronchogenic Carcinoma. J. Cancer, I 1948:634-56.

6. Klopp CT, Alford TC, Bateman J, Berry GN, Winship T. Fractionated intra-arterial cancer; chemotherapy with methyl bis amine hydrochloride; a preliminary report. Ann Surg. 1950;132: 811-32.

7. Donovan TJ. The uses of plastic tubes in the reparative surgery of battle injuries to arteries with and without intra-arterial heparin administration. Ann Surg. 1949;130:1024-43.

8. Creech O Jr, Krementz ET, Ryan RF, Winblad JN. Chemotherapy of cancer: regional perfusion utilizing an extracorporeal circuit. Ann Surg. 1958;148:616-32.

9. Miller TR, Griman OR. Hepatic artery catheterization for liver perfusion. Arch Surg. 1961;82:423-5.

10. Watkins E Jr. Chronometric Infusor-an apparatus for protracted ambulatory infusion therapy. N Engl J Med. 1963;269:850-1.

11. Watkins E Jr, Khazei AM, Nahra KS. Surgical basis for arterial infusion chemotherapy of disseminated carcinoma of the liver. Surg Gynecol Obstet. 1970;130:581-605.

12. Sullivan RD, Norcross JW, Watkins E. Chemotherapy by prolonged hepatic-artery infusion. N Engl J Med. 1964;270:321-7.

13. Sullivan RD, Miller E. The clinical effects of prolonged intravenous infusion of 5-fluoro-2'-deoxyuridine. Cancer Res. 1965;25(7): 1025-33.

14. Lee M. Regional management of liver metastases. I. Cancer Investig. 1983;1:237-57.

15. Blackshear PJ, Rohde TD, Varco RL, Buchwald H. One year of continuous heparinization in the dog using a totally implantable infusion pump. Surg Gynecol Obstet. 1975;141:176-86.

16. Rohde TD, Blackshear PJ, Varco RL, Buchwald H. Protracted parenteral drug infusion in ambulatory subjects using an implantable infusion pump. Trans Am Soc Artif Intern Organs. 1977;23:13-6.

17. Breedis C, Young C. Blood supply of neoplasms in the liver. Am J Pathol. 1954;30:969-85. 
18. Taylor I, Rowling J, West C. Adjuvant cytotoxic liver perfusion for colorectal cancer. Br J Surg. 1979;66:833-7.

19. Swiss Group for Clinical Cancer Research (SAKK) (1995) Longterm results of single course of adjuvant intraportal chemotherapy for colorectal cancer. Lancet 345:349-53.

20. Rougier P, Sahmoud T, Nitti D, Curran D, Doci R, De Waele B, et al. Adjuvant portal-vein infusion of fluorouracil and heparin in colorectal cancer: a randomised trial. Lancet. 1998;351:1677-81.

21. Ensminger WD, Rosowsky A, Raso V. Clinical pharmacological evaluation of hepatic arterial infusions of 5-fluoro-2 deoxyuridine in patients with liver metastases from colorectal carcinoma. Ann Int Med. 1987;107:459-65.

22. Meta-Analysis Group in Cancer. Reappraisal of hepatic arterial infusion in the treatment of nonresectable liver metastases from colorectal cancer. J Natl Cancer Inst. 1996;88:252-8.

23. Adam R, Delvart V, Pascal G, Valeanu A, Castaing D, Azoulay $\mathrm{D}$, et al. Rescue surgery for unresectable colorectal liver metastases downstaged by chemotherapy: a model to predict long-term survival. Ann Surg. 2004;240:644-57.

24. Falcone A, Ricci S, Brunetti I, Pfanner E, Allegrini G, Barbara C, et al. Phase III trial of infusional fluorouracil, leucovorin, oxaliplatin, and irinotecan (FOLFOXIRI) compared with infusional fluorouracil, leucovorin, and irinotecan (FOLFIRI) as first-line treatment for metastatic colorectal cancer: the Gruppo Oncologico Nord Ovest. J Clin Oncol. 2007;25:1670-6.

25. Kusunoki M, Noda M, Yanagi H, Kotera H, Yamamura T. Second-look hepatectomy after 5FU arterial infusion in patients with primary unresectable hepatic colorectal metastases. Int J Oncol. 1997;10:107-11.

26. Sadahiro S, Suzuki T, Tanaka A, Okada K, Kamata H. Koisumi J. Surg Today: Clinical significance of and future perspectives for hepatic arterial infusion chemotherapy in patients with liver metastases from colorectal cancer; 2012.

27. NCI Common Toxicity Criteria Version 2.0 Bethesda, National Cancer Institute, Division of Cancer Treatment, 1999.

28. Meta-Analysis Group in Cancer. Efficacy of intravenous continuous infusion of fluorouracil compared with bolus administration in advanced colorectal cancer. Meta-analysis Group in Cancer. J Clin Oncol. 1998;16:301-8.

29. Thirion P, Michiels S, Pignon JP, Buyse M, Braud AC, Carlson $\mathrm{RW}$, et al. Modulation of fluorouracil by leucovorin in patients with advanced colorectal cancer: an updated meta-analysis. J Clin Oncol. 2004;22:3766-75.

30. de Gramont A, Bosset JF, Milan C, Rougier P, Bouché O, Etienne PL, et al. Randomized trial comparing monthly low-dose leucovorin and fluorouracil bolus with bimonthly high-dose leucovorin and fluorouracil bolus plus continuous infusion for advanced colorectal cancer: a French intergroup study. J Clin Oncol. 1997;15:808-15.

31. Kusunoki M, Yanagi H, Kotera H, Noda M, Yamamura T. Effects of pharmacokinetic modulating chemotherapy using oral UFT and continuous venous 5-FU infusion on the prognosis of irradiated rectal carcinomas with p53 overexpression. Int J Oncol. 1998;13:653-7.

32. Kusunoki M, Yanagi H, Noda M, Yamamura T. The usefulness of pharmacokinetic modulating chemotherapy (UFT plus 5FU) in the treatment of unresectable colorectal carcinomas. Oncol Rep. 1999;6:547-52.

33. Yoshikawa R, Kusunoki M, Yanagi H, Noda M, Furuyama JI, Yamamura T, et al. Dual antitumor effects of 5-fluorouracil on the cell cycle in colorectal carcinoma cells: a novel target mechanism concept for pharmacokinetic modulating chemotherapy. Cancer Res. 2001;61:1029-37.

34. Kusunoki M, Yanagi H, Noda M, Yoshikawa R, Yamamura T. Results of pharmacokinetic modulating chemotherapy in combination with hepatic arterial 5-fluorouracil infusion and oral UFT after resection of hepatic colorectal metastases. Cancer. 2000;89: 1228-35.

35. Ommaya AK. Subcutaneous reservoir and pump for sterile access to ventricular cerebrospinal fluid. Lancet. 1963;2:983-4.

36. Ratcheson RA, Ommaya AK. Experience with the subcutaneous cerebrospinal-fluid reservoir. Preliminary report of 60 cases. N Engl J Med. 1968;279:1025-31.

37. Utz JP. Fungal infections of the central nervous system. Clin Neurosurg. 1966;14:86-100.

38. Rubin RC, Ommaya AK, Henderson ES, Bering EA, Rall DP. Cerebrospinal fluid perfusion for central nervous system neoplasms. Neurology. 1966;16:680-92.

39. Ommaya AK, Rubin RC, Henderson ES, Rall DP, Gieseke FG, Bering EA Jr, et al. A new approach to the treatment of inoperable brain tumors. Med Ann Dist Columbia. 1965;34:455-8.

40. Blackshear PJ, Dorman FD, Blackshear PL Jr, Varco RL, Buchwald $\mathrm{H}$. The design and initial testing of an implantable infusion pump. Surg Gynecol Obstet. 1972;134:51-6.

41. Buchwald H, Grage TB, Vassilopoulos PP, Rohde TD, Varco RL, Blackshear PJ. Intraarterial infusion chemotherapy for hepatic carcinoma using a totally implantable infusion pump. Cancer. 1980;45:866-9.

42. Cohen AM, Wood WC, Greenfield A, Waltman A, Dedrick C, Blackshear PJ. Transbrachial hepatic arterial chemotherapy using an implanted infusion pump. Dis Colon Rectum. 1980;23:223-7.

43. Buchwald H, Rohde TD, Dorman FD, Skakoon JG, Wigness BD, Prosl FR, et al. A totally implantable drug infusion device: laboratory and clinical experience using a model with single flow rate and new design for modulated insulin infusion. Diabetes Care. 1980;3:351-8.

44. Skitzki JJ, Chang AE. Hepatic artery chemotherapy for colorectal liver metastases: technical considerations and review of clinical trials. Surg Oncol. 2002;11:123-35.

45. Szakacs JG, Szakacs JE, Karl RC. Surgical resection versus perfusion in the treatment of metastatic and primary liver tumors. Ann Clin Lab Sci. 1990;20:245-57.

46. Coombs DW, Fine N. Spinal anesthesia using subcutaneously implanted pumps for intrathecal drug infusion. Anesth Analg. 1991;73:226-31.

47. Kemeny MM. The surgical aspects of the totally implantable hepatic artery infusion pump. Arch Surg. 2001;136:348-52.

48. Winkelmüller $\mathrm{M}$, Winkelmüller W. Long-term effects of continuous intrathecal opioid treatment in chronic pain of nonmalignant etiology. J Neurosurg. 1996;85:458-67.

49. Chang AE, Schneider PD, Sugarbaker PH, Simpson C, Culnane M, Steinberg SM. A prospective randomized trial of regional versus systemic continuous 5 -fluorodeoxyuridine chemotherapy in the treatment of colorectal liver metastases. Ann Surg. 1987;206:685-93.

50. Kemeny MM, Hogan JM, Goldberg DA, Lieu C, Beatty JD, Kokal WA, et al. Continuous hepatic artery infusion with an implantable pump: problems with hepatic artery anomalies. Surgery. 1986;99:501-4.

51. Arai Y, Kamimura N, Suyama K. A method to retain subcutaneously the catheter end connected to a new silicon reservoir in intraarterial infusion chemotherapy. Jpn J Cancer Chemother. 1982;9:1838-43.

52. Kumada T, Nakano S. Catheterization for reservoir implantation by puncturing the left axillary artery directly under ultrasound guidance. Nippon Acta Radiol. 1990;12:1617-9.

53. Aubaniac R. Injection intraveineuse sousclaviculaire; advantages et technique. Presse Med. 1952;60:1456.

54. Broviac JW, Cole JJ, Scribner BH. A silicone rubber atrial catheter for prolonged parenteral alimentation. Surg Gynecol Obstet. 1973;136:602-6.

55. Hickman RO, Buckner CD, Clift RA, Sanders JE, Stewart P, Thomas ED. A modified right atrial catheter for access to the 
venous system in marrow transplant recipients. Surg Gynecol Obstet. 1979;148:871-5.

56. Niederhuber JE, Ensminger W, Gyves JW, Liepman M, Doan K, Cozzi E. Totally implanted venous and arterial access system to replace external catheters in cancer treatment. Surgery. 1982;92: 706-12.

57. Miura T, Idezuki S, Wada T. Intraarterial infusion chemotherapy for hepatic carcinoma using a totally implantable infusaid pump. Jpn J Cancer Chemother. 1985;12:1949-61.

58. Vescia S, Baumgärtner AK, Jacobs VR, Kiechle-Bahat M, Rody A, Loibl S, et al. Management of venous port systems in oncology: a review of current evidence. Ann Oncol. 2008;19:9-15.

59. Mansfield PF, Hohn DC, Fornage BD, Gregurich MA, Ota DM. Complications and failures of subclavian-vein catheterization. N Engl J Med. 1994;331:1735-8.

60. Teichgräber UK, Gebauer B, Benter T, Wagner J. Long-term central venous lines and their complications. Rofo. 2004;176: 944-52.

61. Teichgräber UK, Pfitzmann R, Hofmann HA. Central venous port systems as an integral part of chemotherapy. Dtsch Arztebl Int. 2011;108:147-53.

62. Yildizeli B, Laçin T, Batirel HF, Yüksel M. Complications and management of long-term central venous access catheters and ports. J Vasc Access. 2004;5:174-8.

63. Biffi R, Orsi F, Pozzi S, Pace U, Bonomo G, Monfardini L, et al. Best choice of central venous insertion site for the prevention of catheter-related complications in adult patients who need cancer therapy: a randomized trial. Ann Oncol. 2009;20:935-40.

64. Ignatov A, Hoffman O, Smith B, Fahlke J, Peters B, Bischoff J, et al. An 11-year retrospective study of totally implanted central venous access ports: complications and patient satisfaction. Eur $\mathbf{J}$ Surg Oncol. 2009;35:241-6.

65. Newman KA, Reed WP, Schimpff SC, Bustamante CI, Wade JC. Hickman catheters in association with intensive cancer chemotherapy. Support Care Cancer. 1993;1:92-7.

66. Drakos PE, Nagler A, Or R, Gillis S, Slavin S, Eldor A. Low molecular weight heparin for Hickman catheter-induced thrombosis in thrombocytopenic patients undergoing bone marrow transplantation. Cancer. 1992;70:1895-8.

67. Lokich JJ, Becker B. Subclavian vein thrombosis in patients treated with infusion chemotherapy for advanced malignancy. Cancer. 1983;52:1586-9.

68. Köksoy C, Kuzu A, Erden I, Akkaya A. The risk factors in central venous catheter-related thrombosis. Aust NZ J Surg. 1995;65: 796-8.

69. Verso M, Agnelli G, Bertoglio S, Di Somma FC, Paoletti F, Ageno W, et al. Enoxaparin for the prevention of venous thromboembolism associated with central vein catheter: a doubleblind, placebo-controlled, randomized study in cancer patients. J Clin Oncol. 2005;23:4057-62.

70. Bern M, Lokich J, Sabina R, Bothe A Jr, Benotti PN, Arkin CF, et al. Very low doses of warfarin can prevent thrombosis in central venous catheters. Ann Intern Med. 1990;112:423-8.
71. Monreal M, Alastrue A, Rull M, Mira X, Muxart J, Rosell R, et al. Upper extremity deep venous thrombosis in cancer patients with venous access devices: prophylaxis with a low molecular weight heparin (Fragmin). Thromb Haemost. 1996;75:251-3.

72. Couban S, Goodyear M, Burnell M, Dolan S, Wasi P, Barnes D, et al. Randomized, placebo-controlled study of low-dose warfarin for the prevention of central venous catheter-associated thrombosis in patients with cancer. J Clin Oncol. 2005;23:4063-9.

73. Karthaus M, Kretzschmar A, Kroning H, Biakhov M, Irwin D, Marschner N, et al. Dalteparin for prevention of catheter-related complications in cancer patients with central venous catheters: final results of a double-blind, placebo-controlled phase III trial. Ann Oncol. 2005;17:289-96.

74. Di Paolo A, Lencioni M, Amatori F, Di Donato S, Bocci G, Orlandini $\mathrm{C}$, et al. 5-Fluorouracil pharmacokinetics predicts disease-free survival in patients administered adjuvant chemotherapy for colorectal cancer. Clin Cancer Res. 2008;14:2749-55.

75. Capitain O, Asevoaia A, Boisdron-Celle M, Poirier AL, Morel A, Gamelin E. Individual fluorouracil dose adjustment in FOLFOX based on pharmacokinetic follow-up compared with conventional body-area-surface dosing: a phase II, proof-of-concept study. Clin Colorectal Cancer. 2012;11:263-7.

76. Gamelin E, Delva R, Jacob J, Merrouche Y, Raoul JL, Pezet D, et al. Individual fluorouracil dose adjustment based on pharmacokinetic follow-up compared with conventional dosage: results of a multicenter randomized trial of patients with metastatic colorectal cancer. J Clin Oncol. 2008;26:2099-105.

77. Inoue Y, Tanka K, Hiro J, Toiyama Y, Miki C, Kusunoki M. Multicentre phase II study of leucovorin plus pharmacokinetic modulating chemotherapy for metastatic colorectal cancer. Oncol Lett. 2010;1:81-5.

78. Inoue Y, Hiro J, Toiyama Y, Tanaka K, Mohri Y, Kusunoki M. Optimal use of current chemotherapy in multimodality therapy for advanced colorectal cancer. Oncol Lett. 2012;3:363-8.

79. Miwa M, Ura M, Nishida M, Sawada N, Ishikawa T, Mori K, et al. Design of a novel oral fluoropyrimidine carbamate, capecitabine, which generates 5-fluorouracil selectively in tumours by enzymes concentrated in human liver and cancer tissue. Eur $\mathbf{J}$ Cancer. 1998;34:1274-81.

80. Tol J, Koopman M, Cats A, Rodenburg CJ, Creemers GJ, Schrama JG, et al. Chemotherapy, bevacizumab, and cetuximab in metastatic colorectal cancer. N Engl J Med. 2009;360:563-72.

81. Wong R, Cunningham D, Barbachano Y, Saffery C, Valle J, Hickish T, et al. A multicentre study of capecitabine, oxaliplatin plus bevacizumab as perioperative treatment of patients with poor-risk colorectal liver-only metastases not selected for upfront resection. Ann Oncol. 2011;22:2042-8.

82. Benson AB 3rd, Bekaii-Saab T, Chan E, Chen YJ, Choti MA, Cooper HS, et al. Metastatic colon cancer, version 3.2013: featured updates to the NCCN guidelines. J Natl Compr Canc Netw. $2013 ; 11: 141-52$ 